\title{
LOS CÓMICOS ESPAÑOLES Y SUS MEMORIAS: BREVE BALANCE
}

\author{
Juan A. RÍOS CARRATALÁ \\ Universidad de Alicante
}

La redacción de este artículo coincide con la publicación de mi libro Cómicos ante el espejo (Alicante, Universidad, 2001) y después de largos meses de investigación resulta difícil abordar de nuevo un tema aportando algo original. Mi única pretensión es, por lo tanto, responder a la amable invitación de $\mathrm{M}^{\mathrm{a}}$ Ángeles Ayala con un texto que esboza algunas de las razones de un fenómeno editorial de plena actualidad con resultados muy desiguales: la publicación de memorias por parte de los actores españoles. Es obvio que el mismo ha sido estudiado con mucha mayor extensión en mi citado libro, donde también acudo a los antecedentes y, sobre todo, intento presentar una caracterización del actor español durante el franquismo a partir de varias memorias y escritos autobiográficos de cómicos de la misma generación. Valgan estas páginas como una mera muestra de lo allí escrito y, de acuerdo con las prácticas tan habituales en los lanzamientos publicitarios al uso, como resumen de un ensayo que pretende cubrir un hueco inexplicable en nuestra bibliografía crítica.

La autobiografía en España no sólo vive un momento de relativo esplendor desde 1975, sino que también ha sufrido un profundo cambio en sus protagonistas. Frente a la tradición de religiosos, militares y políticos, salpicada por algunos destacados autores literarios, ahora son más frecuentes las memorias de otros sujetos englobados en colectivos sin apenas antecedentes en el género. Entre ellos destacan los actores, algunos de los cuales han obtenido importantes éxitos editoriales y de crítica con la publicación de sus autobiografías. En un breve período hemos asistido a la reedición ampliada de la fundamental obra de Fernando 
Fernán Gómez (El tiempo amarillo, Madrid, Debate, 1998), la aparición de los a veces sorprendentes «aguafuertes» memorialísticos de Miguel Gila ( $Y$ entonces nací yo, Madrid, Temas de Hoy, 1995; Memorias de un exilio, Madrid, Temas de Hoy, 1998), las vitalistas páginas autobiográficas de un «novio de la vida» como Paco Rabal (Si yo te contara, Madrid, El País-Aguilar, 1994) y el sorprendente éxito de ventas de un libro lúcido, polémico y crítico como Tan cerca, tan lejos (Barcelona, Tusquets, 1998), donde Adolfo Marsillach da una auténtica lección de cómo enfrentarse al género que nos ocupa. Otros títulos recientes son encomiables por su intención de abordar el género con un riguroso criterio, como es el caso de las memorias de Teófilo Calle (Ésta es la cuestión, Murcia, Universidad, 2000), y se sitúan al margen del obvio componente comercial que se da en la edición de muchos de estos títulos. También debemos tener en cuenta obras menores, aunque a veces lanzadas espectacularmente por las editoriales gracias al componente «mediático» de sus protagonistas: Antonio Ozores ( $E l$ ciclón de los Ozores, Barcelona, Eds. B, 1998), Jacinto Molina (Memorias de un hombre lobo, Madrid, Alberto Santos Ed., 1997), $\mathrm{M}^{\mathrm{a}}$ Luisa Ponte (Contra viento y marea, Madrid, Ciclo Editorial, 1993), Tony Leblanc (Ésta es mi vida, Madrid, Temas de Hoy, 1999), José Luis de Villalonga (La cruda y tierna verdad, Barcelona, Plaza y Janés, 2000), Luis Escobar (En cuerpo y alma, Madrid, Temas de Hoy, 2000) y Sara Montiel (Memorias, Barcelona, Plaza y Janés, 2000). Otras obras sólo parcialmente relacionadas con la autobiografía, como la de Javier Gurruchaga (Garras humanas, Madrid, El País-Aguilar, 1999) o la de Carmen Sevilla y Paco Rabal (Aquella España dulce y amarga, Barcelona, Grijalbo, 1999), se suman a una ya larga lista que, si pretendiéramos la exhaustividad, también debiera incluir las memorias de actores publicadas en diversas revistas de las llamadas del corazón. Abordarlas, no obstante, sería tanto como conceder una mínima categoría a auténticos subproductos que sólo merecen el olvido, salvo que pretendamos hacer un estudio de la mentalidad de sus lectores o algo similar.

Las causas de la proliferación de los escritos autobiográficos en España desde 1975 ya han sido planteadas en otros trabajos. Algunas de ellas, como las relacionadas con el cambio de valores y la mayor libertad de expresión, afectan obviamente a las obras de unos actores que han debido esperar bastantes años para hacer públicos determinados episodios de sus vidas o manifestar algunas opiniones. Mi objetivo es apuntar algunas de las razones que justifican tan activa y destacada participación de los «cómicos», término asumido por Fernando Fernán-Gómez, Francisco Rabal, Miguel Gila y Adolfo Marsillach, que serán los autores de quienes hablaremos a continuación. Unos cómicos que forman parte del nuevo, amplio y heterogéneo concepto de «los famosos» que como tales son proclives a cultivar este género, pero que han conservado la más restrictiva cate- 
goría de «prestigiosos» como aval para evitar las manifestaciones más vulgares de una escritura autobiográfica a menudo maltratada.

Fernando Fernán-Gómez al iniciar su citada obra se plantea hasta qué punto son interesantes las memorias de un cómico español. Lo hace desde la perspectiva de quien en reiteradas ocasiones ha escrito sobre la marginalidad de su profesión en la historia de España -la marginalidad implica el silencio de quienes la padecen-y duda al carecer de suficientes antecedentes en el contexto nacional. Los únicos realmente válidos, puesto que los ejemplos de Charles Chaplin, Lauren Bacall, Laurence Olivier y otros semejantes pertenecen a un mundo muy alejado del de un cómico durante el período franquista. Estas dudas del reflexivo Fernando Fernán-Gómez casi desaparecen en las obras de sus tres citados colegas y, desde luego, ni siquiera pasan por la mente de un editor actual. La clave de tan radical cambio en pocos años debemos buscarla en la desaparición de dicha marginalidad -máxime cuando se trata de sujetos tan conocidos y respetados-, pero sobre todo en la sustitución del prestigio por la fama a la hora de justificar la pertinencia de unas memorias. Este fenómeno ha producido auténticas aberraciones dentro del género como la publicación de las supuestas memorias de un futbolista de veinte años (Raúl). Pero, al margen de las exageraciones propias del afán comercial de algunas editoriales, ya no es necesario contar con una tradicional noción de prestigio social o intelectual para lanzarse a escribir -o dictar- una autobiografía y publicarla. Lo fundamental, al menos para que los editores se interesen por la obra, es la fama y dentro del concepto «famosos» conviven actualmente los más dispares sujetos. Hay quien la ha conseguido gracias a una trayectoria vital y quien disfruta de una fama pasajera fruto de las más variopintas causas. Pero todos parecen tener el mismo derecho a publicar sus memorias dentro de una democratización del género que, tal vez, acabe perjudicando su interés literario e intelectual.

Frente a casos paradigmáticos de la degeneración de la autobiografía como el del también actor Espartaco Santoni (No niego nada, Barcelona, Capriles, 1990; Digan lo que digan, Barcelona, Ediciones B, 1991), en los cuatro ejemplos que nos ocupan confluyen la popularidad ganada tras unas largas y brillantes carreras con el respeto y hasta la admiración de quienes pueden proporcionar una noción de prestigio. Esta circunstancia favorece el interés de unas obras escritas desde la lucidez, el sentido crítico y la fuerza del testimonio de quienes, protagonistas destacados de una época, son también capaces de valorar los claroscuros de la misma. Los casos de Fernando Fernán-Gómez y Adolfo Marsillach resultan especialmente brillantes en ese sentido y justifican el sentido de un género a menudo maltratado por autores que se limitan a acumular anécdotas triviales y chismorreos. 
No obstante, y al margen de las fundamentales nociones de la fama y el prestigio, las vidas de los actores suelen ser peculiarmente adecuadas para las autobiografías o, mejor dicho, interesantes para los lectores de dicho género. Estos últimos apenas perciben diferencias entre el mismo y una novela, tal y como en repetidas ocasiones han indicado los teóricos de la literatura. Es lógico, pues, que se sientan más atraídos por unos individuos cuya trayectoria profesional, además de pública, es por diversos motivos comparable a los cánones del más tradicional protagonista novelesco. Veamos algunos de ellos.

En los cuatro casos nos encontramos ante unos ancianos que todavía muestran el suficiente vigor para estar presentes en nuestra actualidad cultural -incluso ocupando un destacado lugar-, pero al margen de cualquier inestabilidad o polémica. A estas alturas, y en la faceta que nos ocupa, nadie duda de su valía profesional. Su posición es sólida en todos los sentidos y desde la misma repasan su trayectoria al modo de tantos protagonistas de novelas o películas. Pero, como ocurre con estos últimos, dicha solidez contrasta con los obstáculos que han jalonado una vida repleta de altibajos, triunfos y fracasos. Al igual que en numerosos relatos de ficción, conocemos el desenlace feliz, la brillante culminación de tantos esfuerzos, pero desde ese reconfortante y tranquilizador punto de partida nos interesamos por seguir las azarosas trayectorias de unos profesionales cuyo destino no estaba escrito, ni siquiera previsto.

La profesión de actor implica azar e incertidumbre, dos elementos de gran rentabilidad narrativa. A diferencia de lo que ocurre con otros colectivos donde la lógica de lo previsible deriva en la rutina, el cómico de la época reflejada por los cuatro autores accede a la profesión por caminos salpicados de azar y lucha por la supervivencia. No se trata de una vocación definida que da paso a una formación adecuada para subir al escenario, sino de un conjunto de circunstancias heterogéneas que confluyen en unos individuos que, sobre todo, muestran una decidida voluntad de salir adelante como actores.

Y triunfan, pero -como afirma a menudo Fernando Fernán-Gómez- el triunfo de un actor en la España del franquismo apenas supone seguridad. Es una circunstancia que ha de ser renovada constantemente, lo cual provoca una inseguridad mostrada por estos actores en diversos momentos. Por eso mismo su situación actual, el presente desde el que escriben sus memorias, tiene más mérito a los ojos de un lector que sigue con atención los altibajos y peligros de una trayectoria profesional donde nada está previsto, donde casi todo es posible y que, en definitiva, sólo se salva por la firme voluntad de sus protagonistas. ¿No nos recuerda lo que ocurre con tantas novelas clásicas? 
La lectura de un relato de ficción centrado en un protagonista individual a menudo es una invitación para conocer el contexto en el que se desarrolla su trayectoria, sobre todo cuando mantiene con el mismo una relación crítica o conflictiva. Algo similar ocurre con las autobiografías de nuestros cuatro cómicos. Aunque en activo todavía (mayo, 2001), sus carreras profesionales se desarrollan con un considerable éxito durante el período franquista. Esta circunstancia convierte sus testimonios en una interesante fuente de información para conocer el teatro, el cine y otras manifestaciones culturales de la época, vistas desde la perspectiva de unos protagonistas con suficiente capacidad crítica y de distanciamiento. El éxito no supuso para ellos el adormecimiento de un sentido crítico, que les llevó a menudo a mantener posturas distantes con respecto a la cultura oficial de la época. Por razones ideológicas, políticas, morales y de otra índole los cuatro triunfaron durante el franquismo, pero ninguno de ellos se identificó con una España de la que percibían sus limitaciones en todos los sentidos. Esta actitud se pone de relieve cuando evocan una época sin la aniquiladora nostalgia y sin manifestar tampoco un rechazo total que resultaría demagógico. En los cuatro casos encontramos diferentes niveles de comprensión del pasado, pero todos se sitúan en una perspectiva que permite el análisis de una etapa histórica donde ellos trabajaron y triunfaron dentro de unos límites estrechos, demasiado estrechos a pesar de su relativa situación de privilegio.

En ese marco los cuatro tuvieron que buscar la forma de hacerse un hueco, de sobrevivir mediante un difícil equilibrio entre sus aspiraciones y sus necesidades. Ese obligado posibilismo enriquece unas obras donde no se da la épica del enfrentamiento total -poco compatible con las manifestaciones actuales del género-, sino la comedia o el drama de una cotidianidad donde muchos deseos quedaron ahogados, pero otros de índole personal o profesional se concretaron en estas trayectorias de quienes, a pesar de los problemas, fueron triunfadores. Vemos, pues, una dialéctica parecida a la de tantas novelas protagonizadas por sujetos alejados de los héroes clásicos, enfrentados a una época y un contexto social donde los triunfos y los fracasos se suceden sin que decaiga el ánimo de un protagonista cuyo objetivo final está muy claro. En estos casos es ser actor, triunfar, obtener reconocimiento público y prestigio y, sobre todo, hacerlo en una España diferente, mucho más próxima a sus deseos que aquella donde iniciaron su trayectoria.

Pocos se interesarían por la autobiografía de un triunfador nato que apenas ha tenido problemas para alcanzar sus objetivos. De la misma manera que sin conflicto no hay drama, sin dificultades convenientemente repartidas a lo largo de una trayectoria vital no hay interés para el lector. No cabe duda de que las cuatro 
obras aquí comentadas son ricas en dificultades de todo tipo. Desde las estrictamente profesionales - censura, pobreza del teatro y el cine, condiciones lamentables de trabajo, aislamiento cultural...- hasta las más íntimas, especialmente llamativas en unos sujetos cuya moralidad estaba al margen de la imperante en la época. Resulta duro comprobar las heridas sufridas por estos triunfadores -otros las tienen sin la compensación de alcanzar ese status-, pero al margen de su indudable base real es cierto también que cumplen una función narrativa fundamental para mantener el interés del lector.

A lo azaroso e imprevisible de estas trayectorias vitales debemos sumar lo intenso y hasta aventurero de algunos episodios. En una época especialmente gris donde lo provinciano resultaba omnipresente, Fernando Fernán-Gómez, Paco Rabal, Adolfo Marsillach y Miguel Gila tuvieron la oportunidad de transgredir algunos de los límites tan opresores para la inmensa mayoría de sus coetáneos. Su profesión y el éxito alcanzado les permitían un modo de vida sólo soñado por muchos españoles de entonces, aunque tampoco quepa idealizar una excepción que, aparte de confirmar la regla, estaba a veces cerca de la misma. Apenas se puede hablar de aventuras en el sentido estricto de la palabra, salvo cuando recordamos episodios como el viaje a África de Adolfo Marsillach para pasar las navidades con un misionero español o algunas de las situaciones vividas por Miguel Gila durante la Guerra Civil. Pero, en esa misma línea, la posibilidad de viajar al extranjero ya era excepcional para un español de los años cincuenta. Por su trabajo o por placer, estos actores viajaron constantemente. De las giras teatrales por provincias apenas cabe dar un testimonio costumbrista repleto de pensiones y pobreza, donde sólo un sujeto tan vitalista como Paco Rabal era capaz de protagonizar aventuras propias de la mejor novela erótica anterior a la citada guerra. Pero cuando, como estrellas de nuestro cine, se trasladaron a otros países vivieron una experiencia que en aquellas circunstancias cabe considerar como extraordinaria. A menudo las autobiografías y los libros de viaje se solapan. Los cuatro ejemplos comentados dan testimonio de esta circunstancia, que añade variedad e interés a unos relatos autobiográficos propios de unos profesionales que cambiaban constantemente de lugar de trabajo. Eran, en aquella época y en España, una notable excepción. Ahora no tanto, pero esa circunstancia que enriquece el perspectivismo crítico de los autores nos hace también más atractiva la lectura de sus obras.

Nuestros autores y protagonistas podían transgredir otros límites no menos característicos de la época. Frente a la rígida y represiva moral sexual que imperaba en la España del franquismo, las cuatro autobiografías revelan unos comportamientos íntimos alejados de las pautas seguidas por la mayoría. Mucho se ha 
escrito sobre la condición marginal de los cómicos y su peculiar moral. Fernando Fernán-Gómez es un especialista en el tema desde una perspectiva de defensa de lo que se ha considerado históricamente como una de las señas de identidad del colectivo. Esa postura la comparten los otros tres autores, partícipes activos además de una concepción de las relaciones sentimentales y sexuales al margen de la moral represiva del momento, a pesar de un no menos evidente machismo. La evolución de la sociedad española en esos temas ha restado interés a una oposición que ha perdido vigencia. En un colectivo tan diluido y hasta despersonalizado como lo es en la actualidad el de los cómicos, ya no hay una forma peculiar de entender la moral que sirva como seña de identidad. Pero para el lector actual, más allá del testimonio de una contraposición desaparecida, queda la intensidad de la vida de unos individuos donde se suceden, a veces a ritmo vertiginoso, los amores, los encuentros y los desencuentros. Incluso se llega a casos divertidos como el de Paco Rabal, «un novio de la vida»-según la acertada definición de Fernando Fernán-Gómez- cuya sinceridad al respecto empequeñece lo mostrado por las memorias de Giacomo Casanova. Por ese camino los peligros son obvios y la amenaza del chismorreo asoma, pero la sincera naturalidad de Paco Rabal, la elegancia de Adolfo Marsillach y el estricto pudor de Fernando Fernán-Gómez evitan un peligro que acaba convirtiéndose en un atractivo más de sus obras.

Nuestros cómicos no sólo viajaron y se enamoraron en reiteradas ocasiones de algunas de las mujeres más bellas de la época, sino que en los buenos momentos hicieron ostentación de un poder económico ajeno a la pobreza tan extendida por entonces en España. En una época en la que empezaban a circular los primeros utilitarios, ellos por ejemplo llevaban espectaculares coches que, en los casos de Adolfo Marsillach y Miguel Gila incluso suponían una ostentación un tanto hortera reconocida con el paso de los años. Pero no eran ricos, al menos como los ricos de verdad, aquellos que siempre lo son por encima de circunstancias más o menos pasajeras. Su dinero era tan efímero como, en algunos casos, sus amores. Enriquecerse y arruinarse varias veces es una constante de unas trayectorias propias de una profesión donde resulta imposible hacer planes, donde la continuidad es casi una quimera. De ahí que vivan intensamente al día, disfrutando de aquello que no se sabe si durará, exprimiendo al máximo lo que les depara sus triunfos profesionales porque temen que pronto vengan momentos duros. Las «paradas» -en las que el teléfono deja de sonar sin que se acierte a comprender las causas-, la pérdida de popularidad, la falta de proyectos viables e interesantes, el desconcierto en algunos períodos... fueron circunstancias laborales sufridas por todos ellos. En lo personal, a veces su vida también tuvo momentos difíciles. Miguel Gila se marchó de España para no ser procesado por adúltero, otros padecieron las consecuencias de la inexistencia del divorcio... y siempre sabían que su 
actitud no estaba legitimada, sólo consentida por unos poderes que la recluían en unos colectivos tan reducidos como el de los cómicos. Trabajo, dinero, amor... eran bienes que iban y venían, nunca consustanciales a su condición de actores ya populares y hasta consagrados. Una alternancia capaz de desquiciar en la vida real, pero atractiva para un lector que se adentra en la cambiante suerte de un individuo cuya vida es cualquier cosa menos lineal o rutinaria.

Queda por señalar una última característica que, sin ser peculiar de los cómicos, se suele considerar como necesaria en una profesión que busca la comunicación con el espectador: la seducción. La misma también se percibe en los personajes que protagonizan estas autobiografías, no sólo relacionables con sus autores por las experiencias vividas sino también por el tono y estilo de su expresión, por las estrategias comunicativas empleadas, por un sinfín de pequeños detalles que dan sentido a algo tan inefable como es la seducción. Sin escatimar las imprescindibles dosis de sinceridad y naturalidad, quienes están acostumbrados a recrear tantos personajes también saben cómo seducir al lector con su propio personaje. Cabe escribir unas memorias para contradecir la imagen pública de uno mismo, para mostrar la supuesta «verdadera» personalidad. Pero no es la opción de nuestros cómicos, tal vez porque en sus casos no tenga sentido esa labor de destrucción de una determinada imagen pública. En las obras aquí comentadas se prefiere mantener la misma, pero enriqueciéndola, justificándola, dándole ese contexto que a veces resulta tan necesario para comprender determinadas actitudes. El resultado no es sólo la creación de una personalidad más concreta, sino también más seductora. Los cuatro saben mostrar sus ángulos más sugestivos y, claro está, jugar con la presentación de aquello que pueda resultar más distanciador con respecto al lector. Después de una eficaz tarea de seducción, que con tanto acierto practican los actores en las entrevistas, reportajes y demás medios de promoción, estos autores consiguen que el lector hable de las proezas sexuales de Paco Rabal con una sonrisa de complicidad, disculpe el mal genio de Fernando Fernán-Gómez y comparta todas las polémicas opiniones de Adolfo Marsillach. ¿Un milagro? No, una múltiple seducción para la que estos sujetos están especialmente capacitados gracias a su profesión.

Si nos fijamos en lo dicho hasta ahora, nos encontramos ante unas trayectorias biográficas donde se dan la fama, el éxito, el prestigio, el azar, el conflicto, la aventura, el imprevisto... y otras circunstancias que, a primera vista, son propias del más convencional relato de ficción. Esos conceptos habría que matizarlos en relación con los casos particulares presentados en las autobiografías de los cuatro cómicos. Aunque Francisco Rabal y Miguel Gila a menudo se quedan en la sucesión de anécdotas, mientras que Fernando Fernán-Gómez y Adolfo 
Marsillach compaginan la narración con la reflexión, todos ellos son capaces de transmitir esa necesaria sensación de vida, de referencia real, que debe tener una autobiografía. Se evita así la excesiva estilización de sus propios personajes a partir de un número limitado de rasgos como los arriba citados. Pero esa credibilidad en ningún caso elimina el armazón de unos personajes construidos a base de unos materiales similares a los que hacen atractivos a los de ficción. Por eso, en gran medida, las autobiografías de los cómicos atraen a los lectores, mientras que otros colectivos ni siquiera se plantean en la actualidad la posibilidad de escribir memorias, al menos con el deseo de ser publicadas.

Toda fórmula literaria donde se dan los componentes del éxito y obtiene una respuesta positiva por parte de los lectores tiende a perpetuarse y, lo que es peor, a extenderse hasta límites inadecuados. Tal vez en España estemos asistiendo a una moda pasajera, pero cuando observamos las autobiografías de los actores norteamericanos, por ejemplo, percibimos que la misma puede mantenerse durante décadas. Aquí no hay una industria cinematográfica que determine tanto la orientación de estas memorias y en gran medida la responsabilidad de su publicación todavía radica en el propio autor. En cualquier caso, conviene establecer un criterio selectivo e incluso recomendar a algunos cómicos que se abstengan de ese más o menos consciente ejercicio de narcisismo que supone escribir unas memorias. No se trata de discriminar exclusivamente en función de la calidad profesional de los sujetos. Actores maravillosos pueden protagonizar una trayectoria personal mezquina o anodina. $Y$ a la inversa, aunque es dudoso que el no triunfador encuentre una editorial donde publicar su obra. Se trata de tener el suficiente sentido autocrítico para valorar el interés del testimonio que cada uno pueda aportar y, lo que es más importante, la capacidad para dar cuenta del mismo con un mínimo de reflexión y voluntad estilística.

No olvidemos que cada época, y en lo que se refiere a un colectivo concreto como el de los actores, tiene un número limitado de sujetos que sirven para dar cuenta de la misma. No hace falta acumular, sino seleccionar. Personalidades como las de Fernando Fernán-Gómez y Adolfo Marsillach marcan y definen un período. Tal vez podamos añadir unas pocas más para el mismo. Pero conviene aceptar que la selección predomine sobre la cantidad, salvo que asimilemos las autobiografías a un sinnúmero de anécdotas triviales o al morbo. Esta segunda dirección parece ser la que predomina en unas editoriales que han encontrado un filón y animan a determinados actores a que cuenten sus peripecias, que conversen entre ellos, que polemicen con otros... en una carrera que acabará convirtiendo un noble género en algo cercano al mundo de las revistas del corazón. En cualquier caso, es posible que convivan ambas tendencias y siempre cabe felicitarse 
por el éxito popular y de crítica de obras como las de Adolfo Marsillach y Fernando Fernán-Gómez. Escritas desde el rigor, la lucidez y el sentido crítico, son capaces de interesarnos por un estilo que evidencia la calidad literaria de los autores y por un armazón -de cuyos rasgos más obvios hemos hablado en este artículo- pronto ocultado por la calidad humana de unos individuos que, con distinto sentido del pudor, nos comunican desde sus preocupaciones íntimas hasta las opiniones sobre las cuestiones más comunes. Tal vez la clave sea que nuestro primer impulso a la hora de leer sus obras se relacione con nuestra admiración por su trabajo como actores, pero pronto descubrimos que detrás del mismo hay unas personalidades polifacéticas que desbordan el siempre estrecho mundo de una profesión, unos individuos que han compartido múltiples y heterogéneas experiencias que han ido enriqueciendo sus biografías. Son conscientes de esa riqueza labrada gracias a una voluntad que da sentido a sus trayectorias y nos la condensan en sus obras de ficción (Las bicicletas son para el verano, Yo me bajo en la próxima, iy usted?...) y en sus memorias, tal vez tan de ficción como las anteriores $\mathrm{y}$, por eso mismo, tan igualmente interesantes. 